\title{
Conflicting studies fuel arsenic debate
}

\section{Uncertainties over contaminated groundwater in southern Asia highlight gaps in science.}

\section{BY EUGENIE SAMUEL REICH}

I $\mathrm{t}$ is often called the largest mass poisoning in human history. Yet more than a decade after the discovery that drinking-water wells in Bangladesh are contaminated with naturally occurring arsenic, researchers are still struggling to understand the hydrology and chemistry behind an environmental crisis that affects more than 60 million people in the Bengal Basin.

A paper ${ }^{1}$ in the press in Geophysical Research Letters adds a further piece to the puzzle. It concludes that one factor, man-made ponds, probably does not play a major part in the release of arsenic into groundwater as some geologists have claimed. Yet the mechanism that is responsible remains elusive, in part because of a lack of systematic studies of the region affected by the problem.

Groundwater in sites across south and east Asia contains arsenic at levels that can cause chronic poisoning. Symptoms include skin lesions, respiratory and cardiovascular disease and a range of cancers. From the basins of the Indus River in the west to the Yangtze in China, "almost all the major rivers draining the Himalayas are affected", says Scott Fendorf of Stanford University in California, a biogeochemist who has studied the problem in Cambodia. Residual tectonic activity from the formation of the Himalayas and high rainfall in the region combine to produce rapid erosion, which sweeps arsenic - associated with iron pyrite ores - along with iron oxide particles into river sediment below.

The public-health consequences are most stark in the Ganges delta of Bangladesh, where, in the 1970s, aid agencies encouraged the drilling of hand-pumped wells so that people did not have to drink surface water contaminated with waterborne microbial diseases such as cholera. Geologists failed to realize that the pumps would be tapping into arsenic-laced aquifers beneath.

But just how the arsenic gets into the groundwater is not known. In 2008, a group led by hydrologist Charles Harvey at the Massachusetts Institute of Technology in Cambridge reported $^{2}$ that water from an aquifer in the Munshiganj district of Bangladesh has the same isotopic fingerprint as pond water there, suggesting that organic material may be seeping

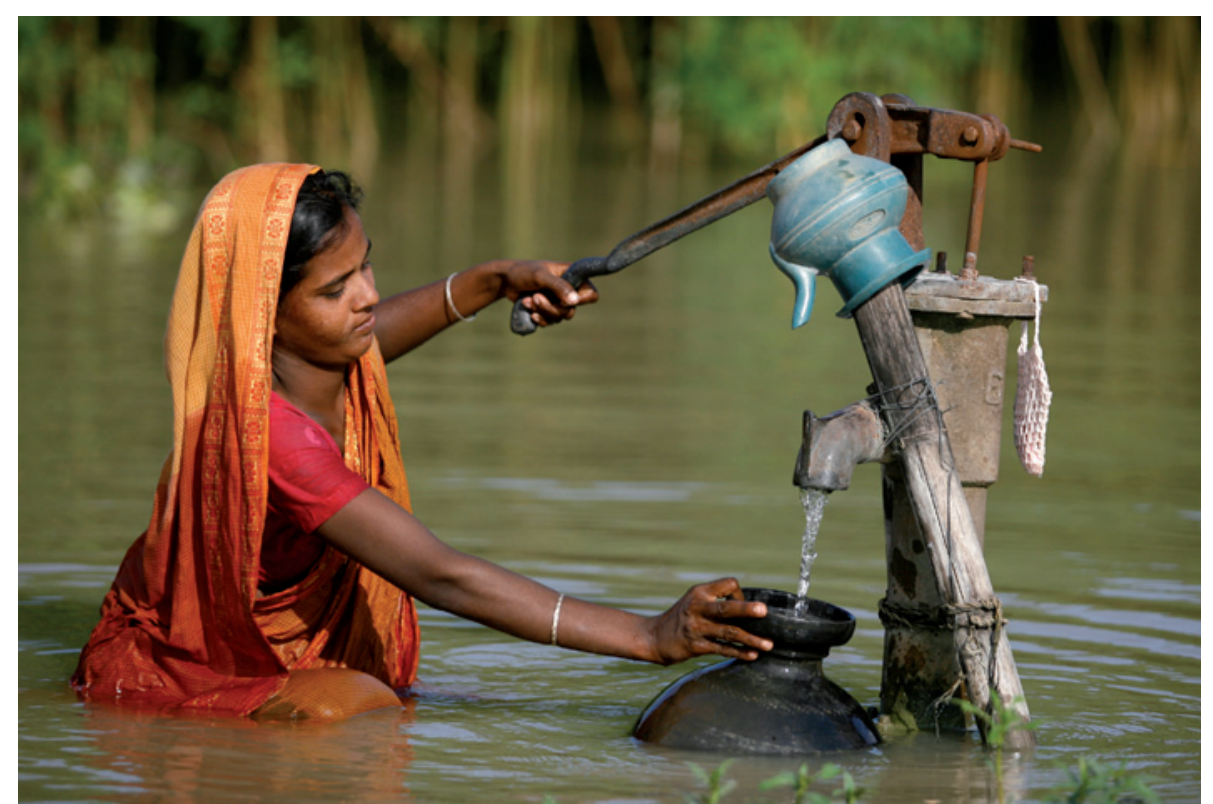

High levels of arsenic in drinking water threaten the health of millions of people living in the Bengal Basin.

from ponds into the aquifer 30 metres below. Harvey proposed that the arsenic is released into the water supply when organic material from ponds triggers microbial activity, which can dissolve the iron oxide particles and release their load of arsenic into the water supply.

The man-made ponds in Bangladesh, a byproduct of excavating earth to build up the land against floodwater caused by the monsoon rains, cover a 22 -fold greater area than

"Almost all the
major rivers
draining the
Himalayas are
affected."
they did 50 years ago, making them a plausible suspect. Harvey and his colleagues suggest that contamination might be reduced if ponds were not dug near wells and if wells were not drilled near existing ponds.

But the finding proved controversial after a group led by geochemist John McArthur at University College London - who failed to see the effect while studying arsenic contamination in West Bengal, India, in 2004 - criticized some of Harvey's team's methods ${ }^{3}$. McArthur and his colleagues reanalysed Harvey's data and arrived at the opposite conclusion. They argued that arsenic was being produced in sediments near the aquifer itself by long-buried organic matter, and that water from ponds was actually flushing out the aquifer and reducing contamination.

The latest study ${ }^{1}$ also suggests that the ponds are not to blame. In their paper, Karen Johannesson of Tulane University in New Orleans, Louisiana, and her colleagues report that six arsenic-laden sites west of the Ganges in West Bengal fail to show signs of organic matter from ponds. The researchers also argue that organic matter from ponds would take thousands of years to penetrate through the tens of metres of clay and sand to the aquifers below, far longer than Bangladeshis have been digging ponds. "I think we feel pretty confident, at least where we're working, that ponds are not contributing," Johannesson says.

But Harvey's and Johannesson's groups worked at widely separated sites, where conditions may differ (see map), says hydrologist Roger Beckie of the University of British Columbia in Vancouver. He suspects that some organic matter is coming from ponds whereas some is intrinsic to the sediments. "My gut feeling is that both processes are at work," he says.

Hydrologist Abhijit Mukherjee at the Indian Institute of Technology in Kharagpur, who is working with West Bengal's government to find ways of predicting where safe wells 
> might be dug, says the dispute shows that government and funding agencies need to support studies at multiple sites, from the Himalayas to the Bay of Bengal. "If that is done we have a systematic way of comparing data from sites," he says.

Whatever the origin of the arsenic, says Stephan Hug, a geochemist at the Swiss Federal Institute of Aquatic Science and Technology in Dübendorf, one possible solution would be to drill deep wells - to below around 150 metres - where the water should be arsenic free. But then if too many such wells are drilled, the arsenic could

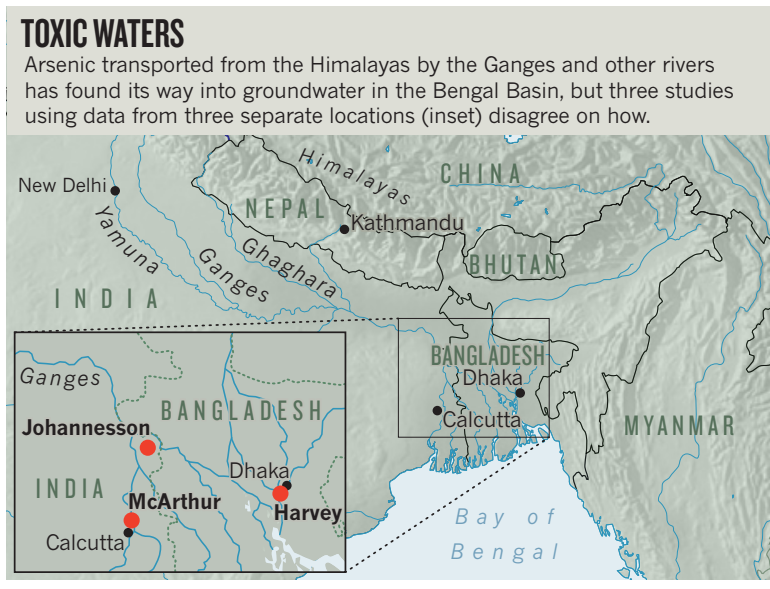

be pulled down to that level, he adds. Moreover, water from such depths can be unacceptably saline.

Mukherjee says that the main goal should be to learn how the arsenic is getting into the groundwater, so that researchers can make wells safe by ensuring that such conditions are avoided. The drinking water of millions of people depends on it.
1. Datta, S. et al. Geophys. Res. Lett. http:// dx.doi.org/10.1029/2011GL049301 (2011).
2. Neumann, R. B. et al. Nature Geosci. 3, 46-52 (2010).
3. McArthur, J. M., Ravenscroft, P. \& Sracek, O. Nature Geosci. 4, 655-656 (2011).

\section{REMUNERATION}

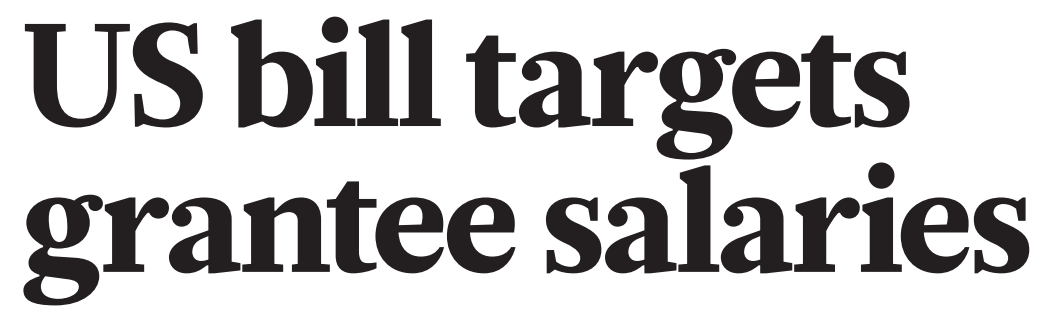

\section{Cost-saving measure would reduce maximum amount paid to biomedical researchers funded by federal agencies.}

\section{BY MEREDITH WADMAN}

$\mathrm{T}$ he US House of Representatives is considering legislation that would roll back the maximum amount of a grant that can go towards the salary of a biomedical researcher funded by a federal agency. Under a spending bill proposed on 29 September, the 'salary cap' would return to what it was roughly ten years ago. If Congress passes the measure, universities and other institutions will face a dilemma: dip into other funds to make up the difference and keep leading investigators happy, or risk losing researchers to industry, clinical practice or competing institutions.

The 2012 spending bill would cut the salary cap by $17 \%$, from US $\$ 199,700$ to $\$ 165,300$, for extramural scientists funded by the National Institutes of Health (NIH; see 'Lowering the ceiling'), the Centers for Disease Control and Prevention and other agencies in the Department of Health and Human Services (DHHS). A parallel Senate bill leaves the salary cap untouched; the two versions must be harmonized before a final 2012 DHHS spending bill is passed. The measures will be considered as part of fraught budget negotiations for financial year 2012.

Just how many scientists would be affected is not clear, but the cut would certainly hit many of the thousands of principal investigators who receive grants from the NIH.

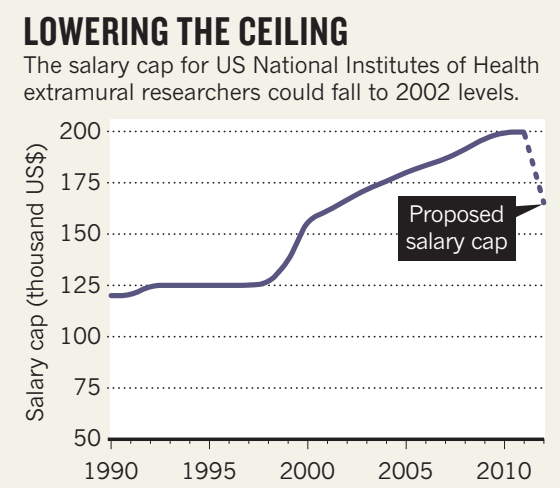

Among medical schools and teaching hospitals, "there is very strong concern about this proposal", says David Moore, senior director for governmental relations at the Association of American Medical Colleges (AAMC) in Washington DC. "If you are a researchintensive institution and you're talking about hundreds of faculty where you have to make up this difference, we're talking about millions of dollars the institution is now responsible for."

On 11 October, the AAMC co-authored a letter to congressional-spending leaders including Denny Rehberg (Republican, Montana), who authored the House bill and is chairman of the subcommittee that funds the DHHS. Signed by 111 organizations and institutions, the letter argues that lowering the salary cap would be most damaging to those investigators who dedicate the most time to research and therefore are most reliant on grants; would discourage gifted young scientists from entering research; and would drive physicians out of research even as demands for cures and therapies are growing.

"Physicians have alternative ways of surviving," notes Moore. "If you continue to put more and more disincentives into a research career, at what point do those individuals say: 'I'm going to go off and see patients?'”

Rex Chisholm, vice-dean for scientific affairs and graduate education at Northwestern University's Feinberg School of Medicine in Chicago, Illinois, says that trying to make up for the cut "would create real difficulties for Northwestern and most other medical schools. Most of us don't have that kind of money just lying around."

He adds that in 2010, Feinberg, which is a signatory to the letter to Congress, paid nearly $\$ 8.3$ million towards the salaries of its 235 faculty members who earned more than the $\$ 199,700$ cap. Had the cap been $\$ 165,300$, he says, the medical school would have had to pay almost $\$ 12$ million to 283 faculty members.

Rehberg did not respond to Nature's requests for comment.

If the cut goes through, says Jeff Gerber, a physician-researcher at the Children's Hospital of Philadelphia in Pennsylvania, "you're either going to have fewer [academic] positions available because the institutions will only be able to pay so many people, or, I suppose, money sometimes drives people into different professional choices". Gerber says that his love for research will probably prevent him ever leaving it. But he expects hospitals to ask physicians to do less research and more income-generating clinical care if grant salaries are cut.

Ironically, the House bill that mandates the cut is far more generous to the NIH overall than is its Senate counterpart. The House bill would boost the biomedical agency's budget by $\$ 1$ billion, or 3.3\%, to $\$ 31.7$ billion. The Senate bill would cut it by $\$ 190$ million. . 